Selling is simply exchanging a product or service

for money, and everyone in a dental practice does

this daily, even if the patient is exempt from

payment.

\title{
Ethical selling - what is it?
}

When I was in general practice I hated the idea of having to 'sell' or being thought of as a salesman. This changed after I left dentistry to work in the financial services industry because I learned what selling was really about, and realised that in dental practice I had been selling all the time. I needed to understand that selling is simply exchanging a product or service for money, and everyone in a dental practice does this daily, even if the patient is exempt from payment. So why do so many people dislike the idea of being considered a salesperson so much?

The answer, to my mind, is that we really only notice when someone is selling to us when that person behaves unethically, usually by trying to persuade us to buy something we do not really want. When someone sells us something we want then we hardly notice what is happening because we are happily involved in buying. As unethical selling is usually to our detriment we then consider all selling to be slightly distasteful because we remember the techniques and results of the unethical salesperson and we do not like them.

The other aspect of selling that tends to worry people is whether it is proactive or reactive. Reactive selling is when you respond to an enquiry from a potential purchaser, such as in a shop or following an advertisement or mailshot. Proactive selling is when you approach someone to try and enter a dialogue with them to discover if they would benefit from your product or services, as I did in my role as a financial consultant. Most people are happier to be a reactive salesperson but less so if they have to be proactive. Dental practice involves both reactive and proactive selling because most patients will come to the practice themselves, but often need dental advice as to what is needed in the way of dental treatment.

Because of this understandable tendency to prefer reactive to proactive selling a great many people in a 'selling situation' prefer to wait until the customer (in dental terms the patient) asks for the product or service. In a shop we prefer to be allowed to browse unless we know what we want or have a specific enquiry. After all, there is nothing more annoying than the persistent shop assistant who continues to badger you with questions or offers of help. However, this approach can be counterproductive in a dental practice for both the dentist and patient if the dentist is waiting to be asked and the patient does not know there is an answer (or even a problem).

For example a patient may require an extraction of an upper premolar, leaving a visible gap. Let us assume there is no clinical reason to replace the missing tooth (in the dentist's opinion). The dentist then assumes that if the patient wants to replace the tooth then the patient will ask, while the patient assumes that if it was possible to replace the tooth then the dentist would offer a solution. The dentist is denying the patient that solution because he does not want to appear 'pushy' and the patient is not being fully informed.

Selling ethically simply means identifying a situation where the dental practice can provide a service for the patient that matches the patient's requirements. This implies asking relevant questions, listening to the patient, examining the patient, and then providing appropriate information in an understandable manner so that the patient can make an informed decision.

This is not as simple as I make it sound, because it requires excellent communication skills to be able to ask the right questions, to listen effectively (the hardest of the skills) and to provide relevant information. The dentist needs judgement, the ability to ask probing questions, the ability to provide information clearly and logically, acceptance of the patient's priorities and an appreciation of what the patient values.

Finally, and crucially, the dentist needs to distinguish between what patients need and what they want, which is not always the same thing. If a patient does not want what they need then we might suppose that attempts to persuade the patient to accept what they need is a form of unethical selling. I shall cover this in more detail in the next leader.

Mike Grace

m.grace@bda-dentistry.org.uk 